\title{
Management of transfusional iron overload - differential properties and efficacy of iron chelating agents
}

This article was published in the following Dove Press journal: Journal of Blood Medicine

20 September 2011

Number of times this article has been viewed

\section{Janet L Kwiatkowski}

The Children's Hospital of Philadelphia, Division of Hematology and University of Pennsylvania School of Medicine, Philadelphia, PA, USA
Correspondence: Janet L Kwiatkowski The Children's Hospital of Philadelphia, 350 I Civic Center Boulevard Division of Hematology, Colket Building, Room I 1024, Philadelphia,

PA 19104, USA

Tel +l 2I5 5905286

Fax + I 2155903992

Email kwiatkowski@email.chop.edu
Abstract: Regular red cell transfusion therapy ameliorates disease-related morbidity and can be lifesaving in patients with various hematological disorders. Transfusion therapy, however, causes progressive iron loading, which, if untreated, results in endocrinopathies, cardiac arrhythmias and congestive heart failure, hepatic fibrosis, and premature death. Iron chelation therapy is used to prevent iron loading, remove excess accumulated iron, detoxify iron, and reverse some of the iron-related complications. Three chelators have undergone extensive testing to date: deferoxamine, deferasirox, and deferiprone (although the latter drug is not currently licensed for use in North America where it is available only through compassionate use programs and research protocols). These chelators differ in their modes of administration, pharmacokinetics, efficacy with regard to organ-specific iron removal, and adverse-effect profiles. These differential properties influence acceptability, tolerability and adherence to therapy, and, ultimately, the effectiveness of treatment. Chelation therapy, therefore, must be individualized, taking into account patient preferences, toxicities, ongoing transfusional iron intake, and the degree of cardiac and hepatic iron loading.

Keywords: transfusion, iron, chelation, magnetic resonance imaging

\section{Iron overload}

\section{Transfusional iron overload}

Regular red cell transfusions are used in the management of numerous hematological disorders including beta-thalassemia major; sickle cell disease; other hemolytic anemias, such as pyruvate kinase deficiency; bone marrow failure syndromes; and myelodysplastic syndromes. Each milliliter of packed red blood cells contains $1.1 \mathrm{mg}$ of iron. Because humans lack physiological mechanisms to excrete excess iron, chronic red cell transfusion therapy will lead to progressive iron accumulation in the absence of chelation therapy. A typical regular transfusion regimen leads to an average iron accumulation of approximately $0.3-0.5 \mathrm{mg} / \mathrm{kg} / \mathrm{day},^{1,2}$ although there is considerable interpatient variability in iron loading. In one study of 541 patients with beta thalassemia, $61 \%$ had transfusional iron intakes in the range $0.3-0.5 \mathrm{mg} / \mathrm{kg} / \mathrm{day}$, while $19 \%$ and $20 \%$ had average iron intakes below and above this range, respectively. ${ }^{1}$ Chelation therapy is necessary to remove this iron accumulation to prevent or treat its associated toxicity.

\section{Nontransfusional iron overload}

Iron overload also can result from hereditary causes that lead to increased intestinal absorption of dietary iron. Dysregulation of hepcidin, a small peptide produced mainly 
in the liver that inhibits iron absorption, now appears to be central in many of the hereditary forms of hemochromatosis. The most common form of hereditary hemochromatosis is caused by mutations in the HFE gene, which prevent the appropriate upregulation of hepcidin expression in response to increased iron levels. ${ }^{3}$ Homozygosity for the cysteine to tyrosine substitution (C282Y) in the human hemochromatosis (HFE) protein is associated with the development of iron overload typically in the fifth to sixth decades of life, although clinical penetrance is variable. ${ }^{4}$ The standard treatment for hereditary hemochromatosis is phlebotomy to reduce iron stores, although iron chelation therapy may be used in patients who are unable to tolerate the procedure. ${ }^{5}$

Gastrointestinal iron absorption also is greatly increased in patients with ineffective erythropoiesis such as thalassemia intermedia and in some red cell enzyme deficiencies, particularly pyruvate kinase deficiency. The pathophysiology may be related to elevated levels of GDF15, a bone marrowderived factor that suppresses hepcidin expression. ${ }^{6,7}$ The resulting increased absorption of dietary iron can cause iron overload, which may be further exacerbated by periodic transfusions. Serial phlebotomy is impractical for many patients with congenital anemias because of the level of anemia, and chelation therapy is effective in reducing iron burden in these patients. ${ }^{8-11}$

The remainder of this review focuses on the management of transfusional iron overload including monitoring and treatment with chelation. The majority of data regarding chelation therapy has been derived from the thalassemia population and is the focus of this review; important differences relevant to other transfused populations are highlighted where possible.

\section{Toxicity related to iron overload}

Free iron is toxic to cells; normally, in the body iron is tightly complexed with proteins, protecting the cells from free iron. The main storage complex of iron is ferritin, which is found principally in the liver, reticuloendothelial cells, and red cell precursors; small amounts of ferritin are also found in the blood, allowing for easy measurement. In plasma, iron is bound to transferrin, which transports iron to the cells. In iron overload states, high levels of iron exceed the ironcarrying capacity of transferrin within the plasma, leading to the formation of nontransferrin-bound iron forms. ${ }^{12}$ These nontransferrin-bound iron forms can be taken up into cells, including liver, heart, and endocrine cells, where the iron can participate in the generation of free radicals through Fenton's reaction:

$$
\mathrm{Fe}^{2+}+\mathrm{H}_{2} \mathrm{O}_{2} \rightarrow \mathrm{Fe}^{3+}+\mathrm{OH}^{-}+\mathrm{HO} \bullet
$$

These free radicals cause lipid peroxidation and organelle damage leading to organ toxicity. The organs most susceptible to iron-related injury include the heart, liver, and endocrine organs. Cardiac toxicity includes congestive heart failure and arrhythmias and is the leading cause of death related to iron overload in patients with thalassemia major. ${ }^{13}$ Excess iron deposition in the liver leads to inflammation, fibrosis, and cirrhosis, ${ }^{14}$ which may be further exacerbated by concomitant viral hepatitis, alcohol use, and other hepatotoxins. Iron is also toxic to the endocrine organs, leading to growth failure, delayed puberty, ${ }^{15}$ hypogonadotropic hypogonadism, diabetes mellitus, osteopenia, hypothyroidism, and hypoparathyroidism. ${ }^{16}$ Endocrinopathies are a significant cause of morbidity in chronically transfused patients: among 342 North American patients with transfusiondependent thalassemia, 38\% had at least one endocrinopathy, most commonly hypogonadism, and the prevalence of endocrine abnormalities increased with age. ${ }^{16}$ Similarly, in a French cohort of 215 chronically transfused patients with thalassemia, 47.8\% had hypogonadism, 6\% diabetes, and $9.9 \%$ hypothyroidism. ${ }^{17}$

\section{Monitoring iron burden}

Multiple methods of assessing the degree of iron overload exist, and each method has benefits and limitations. In clinical practice, combinations of the different techniques and serial measurements are utilized to assess iron burden and to adjust chelation therapy. Tables 1 and 2 provide a summary of the clinical implications of various iron measurements.

Serum ferritin level can be measured frequently via blood testing and is particularly useful to monitor trends in iron burden over time. The ferritin level correlates with total body iron burden in chronically transfused patients, although this correlation is not precise. ${ }^{18}$ Furthermore, changes in the serum ferritin level in response to chelation have been shown to parallel changes in liver iron concentration measured by both liver biopsy and noninvasive means. ${ }^{19,20}$ The ferritin level also has prognostic significance: sustained levels of over $2500 \mathrm{mg} / \mathrm{mL}$ are associated with an increased risk of cardiac toxicity and death in patients with thalassemia. ${ }^{21,22}$

Unfortunately, a variety of disease states, including infection, inflammation, and ascorbate deficiency, can either raise or lower serum ferritin levels. This limitation of ferritin in predicting iron stores is particularly relevant for patients with sickle cell disease. For example, great variability in the rate of rise of serum ferritin level was evidenced among 50 children with sickle cell disease receiving similar transfusion programs 
Table I Clinical implication of ferritin levels and liver iron concentration

\begin{tabular}{|c|c|c|}
\hline $\begin{array}{l}\text { Liver iron } \\
\text { concentration } \\
(\mathrm{mg} / \mathrm{g} \mathrm{dw})\end{array}$ & $\begin{array}{l}\text { Ferritin level }^{\mathrm{a}} \\
(\mathrm{ng} / \mathrm{mL})\end{array}$ & Clinical implications \\
\hline$<2$ & $<500$ & $\begin{array}{l}\text { Low iron stores; consider } \\
\text { decreasing or holding } \\
\text { chelation temporarily }\end{array}$ \\
\hline $2-7$ & $500-1499$ & $\begin{array}{l}\text { Ideal range; continue current } \\
\text { chelation }\end{array}$ \\
\hline$>7-15$ & $1500-2500$ & $\begin{array}{l}\text { Increased iron stores; increase } \\
\text { chelator dose } \mathrm{e}^{\mathrm{c}} \text { and/or change } \\
\text { chelator if ferritin and/or liver } \\
\text { iron trend is not improving }\end{array}$ \\
\hline$>15$ & $>2500$ & $\begin{array}{l}\text { Elevated iron stores } \\
\text { associated with increased risk } \\
\text { of complications and death; } \\
\text { increase chelator dose }{ }^{c} \text { and/ } \\
\text { or change chelator; consider } \\
\text { combination chelation therapy }\end{array}$ \\
\hline
\end{tabular}

Notes: ${ }^{a}$ Ferritin should be obtained when patient is clinically well and vitamin $C$ replete; 'bchelation should not be held if cardiac iron loading is present (cardiac $\mathrm{T} 2 *<20 \mathrm{~ms}$ ) ; chelator dose should not exceed approved range (see Table 3).

for primary stroke prevention..$^{23}$ Despite this limitation, the serum ferritin level still may be useful in sickle cell disease: very high ferritin levels above $3000 \mathrm{ng} / \mathrm{mL}$ generally predict a liver iron concentration of $10 \mathrm{mg} / \mathrm{g}$ dry weight (dw) or higher, while ferritin levels below $1500 \mathrm{ng} / \mathrm{mL}$ usually correlate with a liver iron concentration below $10 \mathrm{mg} / \mathrm{g} \mathrm{dw} .{ }^{24}$ Serum ferritin level also underestimates liver iron concentration in patients with thalassemia intermedia and nontransfusion-associated iron overload. ${ }^{25}$

Given that the liver is the major target organ for iron accumulation following multiple transfusions, the liver iron concentration is a good indicator of total iron burden. ${ }^{26} \mathrm{In}$ untransfused individuals, the normal liver iron concentration

Table 2 Clinical implications of cardiac iron assessment by T2* magnetic resonance imaging

\begin{tabular}{ll}
\hline Cardiac T2* (ms) & Clinical implication \\
\hline$\geq 20$ & No significant cardiac iron loading; continue \\
& current chelation \\
& Mild to moderate cardiac iron loading with \\
& increased risk of cardiac complications; \\
& consider intensification of chelation such as \\
& increased dose ${ }^{\text {a }}$ and/or continuous infusion \\
& (for deferoxamine); combination therapy with \\
& deferiprone and deferoxamine if available \\
& Severe cardiac iron loading with high risk of \\
& cardiac complications; intensify chelation such \\
& as increased dose ${ }^{\mathrm{a}}$ and/or continuous infusion \\
& (for deferoxamine); combination therapy with \\
& deferiprone and deferoxamine if available \\
\hline
\end{tabular}

Note: ${ }^{a}$ Chelator dose should not exceed approved range (see Table 3). ranges from 0.17 to $1.8 \mathrm{mg} \mathrm{Fe} / \mathrm{g} \mathrm{dw}$. Traditionally, chelation therapy has been dosed to maintain slightly higher liver iron concentrations of 3 to $<7 \mathrm{mg} \mathrm{Fe} / \mathrm{g} \mathrm{dw}$ of liver, a level of hepatic iron burden that is seen in asymptomatic heterozygotes for hereditary hemochromatosis. ${ }^{27}$ More aggressive chelation regimens have been advocated recently, with a goal to achieve and maintain "normal" body iron stores, ${ }^{28}$ although the risk of toxicity with "overchelation" must be considered. Liver iron concentration also has prognostic significance in patients with thalassemia. Levels in excess of $15 \mathrm{mg} \mathrm{Fe} / \mathrm{g} \mathrm{dw}$ of liver are associated with an increased risk of cardiac complications and death, ${ }^{21,22}$ although the inverse is not always true: high levels of cardiac iron and iron-related cardiac disease can be seen despite low liver iron concentrations, due to differential rates of iron loading and unloading in these organs. ${ }^{29,30}$

Various methods are available to estimate liver iron concentration. Liver biopsy is generally considered to be the gold standard for accurate iron measurement and allows for direct assessment of liver inflammation and fibrosis. However, a number of limitations to liver biopsy exist: it is an invasive procedure, with risks including bleeding, bile leak, and pain; liver fibrosis and cirrhosis cause an uneven distribution of iron, which may lead to an underestimation of liver iron in patients with advanced liver disease; ${ }^{31}$ and sample size also affects the accuracy of iron measurement samples that are at least $1 \mathrm{mg} \mathrm{dw}$ correlate better with iron burden than do smaller samples. ${ }^{26}$

The superconducting quantum interference device (SQUID) technique uses magnetometers to measure very small magnetic fields and can be used as a noninvasive technique to measure ferritin and hemosiderin in the liver. ${ }^{32}$ Estimation of liver iron concentration by SQUID correlates linearly with concentrations measured by liver biopsy. ${ }^{32}$ Since this is a noninvasive technique, repetitive iron concentration measurements by SQUID have been utilized to monitor the efficacy of chelation in a number of studies. ${ }^{20,33-35}$ The biggest limitation to using SQUID is that it is a highly specialized and expensive approach and few sites worldwide offer the technology, limiting its accessibility to patients. In recent clinical trials, SQUID measurements also underestimated liver iron concentrations obtained by biopsy by approximately $50 \%,{ }^{19}$ though the correlation is good when accurate conversion factors from wet to dry weight of liver are utilized. ${ }^{36}$

Magnetic resonance imaging (MRI) is increasingly being used to monitor iron overload. This technique takes advantage of local inhomogeneities of the magnetic field caused by iron deposition in tissues. ${ }^{37}$ Magnetic resonance 
images darken at a rate proportional to the iron concentration. T2 and T2* refer to the half-life of darkening and these values are inversely proportional to the amount of iron accumulation in the organ. The reciprocals of T2 and T2*, known as R2 and R2*, respectively, refer to rates of signal decay and are directly proportional to iron concentration. ${ }^{38}$ While MRI has been used to estimate iron levels in a variety of organs including the pituitary, pancreas, and bone marrow, it is most commonly used to measure hepatic ${ }^{39}$ and cardiac iron. ${ }^{29,40}$ Studies using R2 to estimate liver iron have shown good correlation with iron levels determined by liver biopsy, as well as reproducibility across different scanners. ${ }^{39}$ Other approaches using T2* or R2* are also promising for determining liver iron content..$^{29,41}$

Most important, cardiac iron levels also can be estimated using MRI, most commonly with T2* measurements. Determination of cardiac iron is particularly helpful because cardiac disease is the leading cause of death in patients with thalassemia and transfusional iron overload. ${ }^{13}$ Cardiac T2* values below $20 \mathrm{~ms}$ indicate mild to moderate cardiac iron overload, while levels below $10 \mathrm{~ms}$ are associated with an increased risk of cardiac disease including ventricular dysfunction and arrhythmias (Table 2). ${ }^{29,40}$ Patients with T2* values below $6 \mathrm{~ms}$ have a $47 \%$ chance of developing congestive heart failure within the next year. ${ }^{42}$ Thus, patients with low cardiac $\mathrm{T} 2 *$ values require intensification of chelation therapy.

Magnetic resonance scanners are more widely available than SQUID, and this technique is now available in many sites throughout the world. Limitations include the need for specialized programming and expertise in these MRI techniques. In addition, MRI is costly, making frequent monitoring prohibitive.

Most knowledge of the complications of iron overload comes from patients with thalassemia who require lifelong red blood cell transfusions, which are usually initiated within the first few years of life. Patients with different diseases requiring chronic transfusions, particularly sickle cell disease and Diamond-Blackfan anemia, appear to differ somewhat with respect to organ-specific transfusional iron loading. ${ }^{43-45}$ For example, iron-related cardiomyopathy and diabetes are less common in sickle cell disease than thalassemia despite comparable transfusion burdens, ${ }^{43,46}$ a finding that is paralleled by reduced iron loading in the heart and pancreas in sickle cell patients. ${ }^{44,47}$ In contrast, it was observed that liver iron concentration was higher in transfusion-dependent Diamond-Blackfan anemia patients than in thalassemia patients matched for age and iron intake. ${ }^{45}$ Variability in the duration of iron exposure, treatment with chelation, or processing of iron among underlying disease states may all contribute to the differences in organ-specific iron loading. Nonetheless, given the lack of substantial information about disease-specific responses to iron overload, data from the thalassemia population continue to guide monitoring and treatment for other transfused patient populations, although ongoing research studies may provide future insight into better disease-specific approaches.

\section{Overview of chelation}

The goal of chelation therapy is to maintain "safe" body iron levels to prevent the development of organ toxicities. Ideally, for patients who are regularly transfused, chelation should be administered in a manner to prevent excess iron accumulation by matching the ongoing transfusional iron intake. Chelators also bind nontransferrin-bound iron forms, protecting vulnerable organs such as the heart from damage by these toxic iron forms, and continuous chelator exposure is optimal in this regard. In practice, however, chelation therapy is often utilized to remove excess stored iron. Once iron-related organ toxicity has developed, chelation therapy can reverse some, but not all, of the complications. ${ }^{28,48}$

\section{Differential properties of chelators}

A variety of factors differentiate the currently available iron chelators. First, pharmacological properties, including the stoichiometry of iron chelation, mode of administration, dosing schedule, plasma half-life, and route of excretion, vary among chelators. Second, drug efficacy is variable, particularly with regard to organ-specific (hepatic, cardiac) iron removal. Third, adverse-effect profiles differ among chelators. These various drug properties ultimately contribute to patient adherence, overall control of iron burden, and the complication profile. Differential properties of the iron chelators are summarized in Table 3 and the following sections provide detailed information for each of the currently available iron chelators. Chelation therapy needs to be individualized; the choice of chelator(s) and dosing should be made based on: drug availability and tolerability (including adverse effects), patient preference and ability to adhere to the regimen, ongoing transfusion burden, and trends in organ-specific iron loading.

\section{Deferoxamine}

\section{Pharmacology}

Deferoxamine, a naturally occurring iron chelator produced by Streptomyces pilosus, was the first approved iron chelator 
Table 3 Properties of iron chelators

\begin{tabular}{|c|c|c|c|}
\hline Property & Deferoxamine & Deferasirox & Deferiprone \\
\hline $\begin{array}{l}\text { Stoichiometry } \\
\text { (chelator: iron) }\end{array}$ & Hexadentate $(\mathrm{I}: \mathrm{I})$ & Tridentate $(2: 1)$ & Bidentate $(3: 1)$ \\
\hline Usual dose & $\begin{array}{l}25-60 \mathrm{mg} / \mathrm{kg} / \mathrm{day} \\
\text { over } 8-24 \text { hours }\end{array}$ & $\begin{array}{l}20-40 \mathrm{mg} / \mathrm{kg} / \mathrm{day} \\
\text { once daily }\end{array}$ & $\begin{array}{l}75-100 \mathrm{mg} / \mathrm{kg} / \mathrm{day} \\
\text { in three divided doses }\end{array}$ \\
\hline Route of administration & Subcutaneous, intravenous & Orally dispersible tablet & Oral tablet or suspension \\
\hline Half-life & 20-30 minutes & $7-16$ hours & I.5-2.5 hours \\
\hline Excretion & Urinary, fecal & Fecal & Urinary \\
\hline Ability to remove liver iron & +++ & +++ & $++^{*}$ \\
\hline Ability to remove cardiac iron & $++^{\#}$ & $++^{* *}$ & +++ \\
\hline \multirow[t]{9}{*}{ Typical adverse events } & Local reactions & Gastrointestinal & Gastrointestinal \\
\hline & Sensorineural hearing loss & Rash & Neutropenia/Agranulocytosis \\
\hline & Ophthalmic changes & Rise in creatinine & Arthralgia \\
\hline & Allergic reactions & Proteinuria & Elevated hepatic enzymes \\
\hline & Bone abnormalities & Elevated hepatic enzymes & \\
\hline & Increased risk of Yersinia & Gastrointestinal bleeding (rare) & \\
\hline & and Klebsiella infections & Fulminant hepatic failure (rare) & \\
\hline & Pulmonary at high doses & Renal insufficiency (rare) & \\
\hline & Neurological at high doses & & \\
\hline Availability & Licensed & Licensed & $\begin{array}{l}\text { Licensed in Europe and Asia as } \\
\text { second-line agent; not licensed in North America }\end{array}$ \\
\hline
\end{tabular}

Notes: *Reports of insufficient liver iron removal in some patients at doses of $75 \mathrm{mg} / \mathrm{kg} /$ day, but higher dosing, especially for subjects with high transfusional iron burden may be more effective; " with continuous infusion; **data are limited regarding efficacy with very low cardiac T2* and in heart failure; cardiac iron removal also may be less effective in patients with high liver iron concentration.

and has been used in routine clinical practice for more than 40 years. ${ }^{49}$ It is a hexadentate iron chelator that binds iron stably in a 1:1 ratio (Table 3 ). Deferoxamine is not well absorbed from the gastrointestinal tract so it must be administered parenterally. ${ }^{50}$ Furthermore, the drug's plasma half-life is very short at approximately 20 minutes..$^{50}$ Thus, deferoxamine is usually administered as a continuous infusion of 25 to $50 \mathrm{mg} / \mathrm{kg}$ given over 8 to 12 hours, 5 to 7 days per week either subcutaneously or intravenously. Because the drug's half-life is short, the chelator is rapidly cleared after the infusion is completed and the drug is no longer available to bind and detoxify iron. Thus, intravenous administration of longer durations of up to 24 hours daily is often employed for patients with high iron burden and/ or evidence of cardiac iron loading or iron-related cardiac toxicity. Very high dosing of deferoxamine (such as $10 \mathrm{mg} / \mathrm{kg} /$ hour) has been utilized in the past. ${ }^{51}$ However, acute pulmonary and neurotoxicity may develop with higher doses, ${ }^{52,53}$ so, in general, doses $>60 \mathrm{mg} / \mathrm{kg} /$ day should be avoided. Excretion of iron bound to deferoxamine occurs through both the urine and feces.

The parenteral mode of administration is painful and time consuming, which can adversely affect treatment adherence. To overcome this limitation, alternative modes of administration have been investigated. Twice-daily bolus injections of $1000 \mathrm{mg}$ of deferoxamine diluted in $10 \mathrm{~mL}$ of distilled water have been administered. Iron excretion with bolus injection was similar to that seen with subcutaneous infusion. ${ }^{54}$ Unfortunately, painful swelling that lasted for several hours following injection led many patients to discontinue this treatment ${ }^{55}$ and, thus, this mode of administration is infrequently utilized.

\section{Efficacy}

The efficacy of deferoxamine is well established. The drug induces substantial iron excretion and can induce a net negative iron balance ${ }^{56}$ in chronically transfused patients. Iron excretion is hindered in the presence of vitamin $\mathrm{C}$ deficiency, a common consequence of iron overload. Oral supplementation with vitamin $\mathrm{C}$ increases urinary iron excretion with deferoxamine, but excessive vitamin $\mathrm{C}$ can also increase the toxicity of iron. ${ }^{57}$ Thus, patients with documented vitamin $\mathrm{C}$ deficiency are usually treated with $100 \mathrm{mg}$ of vitamin C orally, given only at the time of deferoxamine infusion. Multiple studies dating back over three decades have shown that regular administration of deferoxamine effectively lowers serum ferritin levels. ${ }^{19,58,59}$ Chelation therapy with deferoxamine can also prevent other organ toxicities such as diabetes and other endocrinopathies. ${ }^{49,60}$

\section{Hepatic iron removal}

In the 1970s, regular intramuscular administration of deferoxamine therapy was shown to reduce hepatic iron 
accumulation and slow the progression of hepatic fibrosis. ${ }^{61}$ Subsequently, in the early 1980s, daily subcutaneous continuous infusion of deferoxamine was shown to reduce hepatic iron content to normal or near-normal levels in chronically transfused patients with thalassemia. ${ }^{62}$ Recent clinical trials have continued to show the efficacy of deferoxamine in hepatic iron removal in patients with transfusion-dependent anemias. ${ }^{19,20}$ Nonetheless, the improvement in liver iron concentration correlates with the rate of transfusional iron intake. ${ }^{1}$ Patients with higher transfusional iron intake generally require more chelator, which may be achieved by administering deferoxamine for a greater number of days per week and/or at the higher end of the therapeutic dose range.

\section{Cardiac iron removal}

Most important, the regular use of deferoxamine is associated with a reduced incidence of cardiac complications and death. ${ }^{21,49,59}$ In addition, deferoxamine, usually given in higher doses up to $60 \mathrm{mg} / \mathrm{kg} /$ day as a continuous intravenous infusion, can reverse cardiac complications. ${ }^{63}$ Cardiac iron burden as measured by T2* MRI also improves with continuous infusion of deferoxamine. ${ }^{48}$

\section{Adverse effects}

Local infusion site reactions, including induration and erythema, are commonly seen with administration of deferoxamine. Allergic reactions can also develop. Other adverse effects - including high-frequency hearing loss; ophthalmologic toxicity; ${ }^{64}$ growth retardation; and skeletal changes, including rickets-like lesions and genu valgum in growing children ${ }^{65}$ - are more common when patients receive high doses of deferoxamine relative to their total body iron burden. Ocular and audiological toxicity can be minimized by maintaining a ratio of deferoxamine dose (mg per $\mathrm{kg}$ of body weight) to the serum ferritin level below $0.025 .{ }^{66}$ Increased risk of infection with Yersinia and Klebsiella species in patients with iron overload may be exacerbated by use of this chelator. ${ }^{67,68}$ Low zinc levels can also develop with deferoxamine use, and levels of this trace element should be measured periodically. Acute pulmonary toxicity with respiratory distress, hypoxemia, and a diffuse interstitial pattern on chest roentgenogram, and acute neurotoxicity have both been reported with the administration of very high doses of deferoxamine $(10-20 \mathrm{mg} / \mathrm{kg} / \mathrm{hr}){ }^{52,53}$

\section{Adherence}

The greatest challenge with deferoxamine is patient adherence, because the need for parenteral administration is cumbersome, uncomfortable, inconvenient, and time consuming. A recent review of published studies showed compliance rates with deferoxamine to range from $59 \%$ to $78 \% .{ }^{69}$ Older age ${ }^{70}$ and concomitant psychiatric disorders ${ }^{71}$ have been found to predict poor adherence. Patient-reported reasons for missing deferoxamine doses included patients' feelings and beliefs, adverse effects, and lack of support from others. ${ }^{70}$ Considerable morbidity and preventable, premature iron-related deaths continue to occur in patients treated with deferoxamine, which are probably related to difficulties with adherence. $^{72,73}$

\section{Deferiprone}

\section{Pharmacology}

Deferiprone (1,2-dimethyl-3-hydroxypyrid-4-one), introduced into clinical trials in the 1980s, was the first oral chelator to undergo extensive testing. This chelator was designed by modifying siderophore chemistry. ${ }^{74}$ Most studies of the drug have involved open-label, noncomparative studies, often including patients with a history of inadequate iron chelation, but a few randomized trials comparing deferiprone with deferoxamine have been reported. A substantial amount of data on the safety and efficacy of the drug has been acquired but considerable controversy surrounds the drug. Deferiprone is approved for use in the European Union and other countries for patients in whom deferoxamine therapy is inadequate or not tolerated, but the drug has not been approved for use in North America and is currently only available to a limited number of patients through compassionate use programs or research trials.

Deferiprone is a bidentate chelator, meaning that three molecules of the drug are required to bind iron fully. Given its relatively short plasma half-life of 1.5 to 2.5 hours, ${ }^{75,76}$ the drug usually is dosed three times daily. The typical daily dose is $75 \mathrm{mg} / \mathrm{kg}$, but doses of up to $100 \mathrm{mg} / \mathrm{kg} /$ day are approved in Europe. The drug is available as $500 \mathrm{mg}$ tablets or as an oral solution $(100 \mathrm{mg} / \mathrm{mL})$, which has been shown to have a similar safety and efficacy profile to the tablet form. ${ }^{77}$ Deferiprone induces iron excretion almost exclusively in the urine, with minimal contribution from fecal elimination. ${ }^{78,79}$

\section{Efficacy}

Urinary iron excretion with deferiprone at doses of $75 \mathrm{mg} / \mathrm{kg}$ is comparable to that induced by deferoxamine at a dose of $50 \mathrm{mg} / \mathrm{kg} .{ }^{78,79}$ The mean urinary iron excretion with deferiprone at $75 \mathrm{mg} / \mathrm{kg}$ was $0.48 \mathrm{mg} / \mathrm{kg} / \mathrm{day}$ in one study, ${ }^{78}$ a level that would be predicted to maintain or 
decrease iron stores in most patients; however, significant interpatient variability exists. Higher doses of deferiprone, $90-119 \mathrm{mg} / \mathrm{kg}$, induced greater urinary iron excretion and may be beneficial for patients with inadequate responses at lower doses. ${ }^{80-82}$ Current European product labeling, however, cautions against using doses above $100 \mathrm{mg} / \mathrm{kg} /$ day due to the potential for increased toxicity.

Short- and long-term studies of treatment with deferiprone for transfusional iron overload have generally shown a reduction $^{35,80,83-86}$ or stabilization ${ }^{87-89}$ in mean serum ferritin levels. Similar responses have been shown across different disease states including sickle cell disease and thalassemia. However, a small proportion of patients demonstrated a significant increase in serum ferritin levels while receiving long-term deferiprone. ${ }^{35,86,88,89}$ In a group of 151 Italian patients who received deferiprone for 3 years or more, $20 \%$ had clinically significant rises in ferritin levels. ${ }^{86}$

\section{Hepatic iron removal}

Studies on the effect of chelation with deferiprone on liver iron concentration have also shown mixed results. ${ }^{35,84,88,90,91}$ In a report of 21 patients who received deferiprone at $75 \mathrm{mg} / \mathrm{kg} /$ day, mean liver iron concentration assessed by biopsy or SQUID, decreased from 15 to $8.7 \mathrm{mg} / \mathrm{g}$ dw liver, after a mean treatment duration of 3.1 years. ${ }^{35}$ With longer follow-up of a mean of 4.6 years in 18 patients, there was an overall reduction in liver iron concentration from baseline (16.5-12.1 mg/g dw, $P=0.07)$, but the liver iron concentration still remained at a concerning level above $15 \mathrm{mg} / \mathrm{g} \mathrm{dw}$ in seven patients. ${ }^{91}$ In another report of 20 patients who received deferiprone $(70 \mathrm{mg} / \mathrm{kg} /$ day $)$ for 1 year or more, the mean liver iron concentration increased from 16 to $21 \mathrm{mg} / \mathrm{g} \mathrm{dw}$, although this change did not reach statistical significance. ${ }^{90}$ Liver iron content decreased in seven patients, rose in 12 patients, and remained the same in one patient. Thus, chelation with deferiprone at a dose of 70-75 mg/ $\mathrm{kg} /$ day may not reduce liver iron concentration effectively in some patients.

Although there are few randomized trials comparing deferiprone with deferoxamine, these studies have generally shown the two drugs have comparable efficacy with regard to hepatic iron removal. In one study of 144 subjects, the reduction in serum ferritin levels was similar between treatment groups (deferiprone $75 \mathrm{mg} / \mathrm{kg}$ /day compared with deferoxamine $50 \mathrm{mg} / \mathrm{kg} /$ day) and mean reduction in liver iron concentration was also similar among a subset of 36 subjects who underwent liver biopsy. ${ }^{84}$ Similarly, in a more recent study of 61 patients randomized to receive either deferoxamine at $50 \mathrm{mg} / \mathrm{kg} /$ day for 5 days per week or deferiprone
( $75 \mathrm{mg} / \mathrm{kg} /$ day initially, then increasing to $100 \mathrm{mg} / \mathrm{kg} /$ day) changes in liver iron concentration over the 1 -year period did not significantly differ between the two groups. ${ }^{92}$

The lack of reduction in serum ferritin levels or liver iron concentration in some patients receiving deferiprone may be explained by a variety of reasons including individual differences in pharmacokinetics, inadequate adherence with therapy, or higher transfusional iron intake. Increasing the dosage of deferiprone might help overcome some of these issues. In one study, increasing the daily dose of deferiprone from $75 \mathrm{mg} / \mathrm{kg}$ to $83-100 \mathrm{mg} / \mathrm{kg}$ resulted in a reduction in serum ferritin level in nine patients who had received inadequate chelation at the lower dose. ${ }^{82}$ Similarly, in a study of twelve transfused thalassemia patients, the mean serum ferritin level significantly improved from $3901 \mathrm{ng} / \mathrm{mL}$ to $2205 \mathrm{ng} / \mathrm{mL}$ after 2 years of treatment with deferiprone at $100 \mathrm{mg} / \mathrm{kg} /$ day and no increased toxicity was observed. ${ }^{93}$

\section{Cardiac iron removal}

Deferiprone is a small molecule that is lipophilic, enabling entry into myocytes, and this chelator appears to be particularly efficacious in cardiac iron removal. Retrospective studies have demonstrated reduced cardiac morbidity and mortality ${ }^{94,95}$ and lower myocardial iron deposition ${ }^{96}$ among patients treated with deferiprone compared with deferoxamine. Furthermore, in a randomized controlled trial of 61 beta-thalassemia patients with moderate cardiac siderosis (T2* 8 to $<20 \mathrm{~ms}$ ) and normal cardiac function, a significantly greater improvement in cardiac $\mathrm{T} 2 *$ and left ventricular function was seen with treatment with deferiprone compared with deferoxamine. ${ }^{92}$ In a large clinical observational study, treatment with deferiprone resulted in improvement in cardiac T2* among patients with all degrees of cardiac iron loading (including severe iron loading with $\mathrm{T} 2 *<8 \mathrm{~ms}$ ) and treatment with deferiprone resulted in a significantly greater overall reduction in cardiac iron compared with deferasirox. ${ }^{97}$

\section{Adverse effects}

The most serious adverse event associated with deferiprone is agranulocytosis. In a multicenter study of 187 patients with thalassemia major treated with deferiprone in which weekly blood counts were monitored, the incidence of agranulocytosis (absolute neutrophil count $<500 \times 10^{9} / \mathrm{L}$ ) was 0.6 per 100 patient-years and the incidence of milder neutropenia (absolute neutrophil count 500 to $1500 \times 10^{9} / \mathrm{L}$ ) was 2.8 per 100 patientyears. ${ }^{87}$ In the largest study reported to date, similar rates of 
0.2 per 100 patient-years for agranulocytosis and 2.1 per 100 for neutropenia were reported. ${ }^{86}$ Neutropenia is usually reversible with discontinuation of the drug but often recurs with reinstitution of therapy. ${ }^{86,98}$ In clinical practice, weekly blood counts are recommended, which can be inconvenient for patients, to monitor for this side effect. Treatment with deferiprone may not be appropriate for patients with underlying bone-marrow failure syndromes, such as DiamondBlackfan anemia or myelodysplastic syndromes, who may be more likely to develop agranulocytosis or neutropenia..$^{99,100}$ Similarly, caution should be exercised when using this drug in combination with hydroxyurea, interferon, or other drugs that can cause neutropenia.

Gastrointestinal symptoms including nausea, vomiting, diarrhea, and abdominal pain are common side effects reported with deferiprone, occurring in 33\% of subjects in one large study. ${ }^{89}$ These symptoms usually improve after the first few weeks of treatment and rarely require discontinuation of therapy. ${ }^{86,87}$ Arthropathy with pain and/or swelling of the knees and other large joints is another common complication, and can occur early or late in treatment. ${ }^{85,86,89}$ In a large study of 532 patients, the prevalence of this complication was only $4 \%,{ }^{86}$ but other studies have reported higher rates of up to $38.5 \% .{ }^{80}$ The arthropathy is usually reversible with discontinuation of the drug. ${ }^{80,87}$ Low plasma zinc levels have also developed in a minority of patients receiving deferiprone, thus periodic monitoring of zinc levels is warranted..$^{80,87}$

Elevations in serum alanine aminotransferase (ALT) can occur with drug administration but are often transient and resolve even with continued drug administration at the same or reduced dose. ${ }^{85,86}$ Patients with hepatitis $\mathrm{C}$ infection ${ }^{86,87}$ or higher hepatic iron concentrations ${ }^{86}$ may be more likely to develop ALT elevations. Concerns have been raised about the possible progression of hepatic fibrosis with deferiprone therapy. ${ }^{91}$ In a retrospective study, progression of hepatic fibrosis was seen among five of 14 patients after a mean duration of 2.3 years of treatment with deferiprone; four of the subjects with progression of fibrosis also had concomitant hepatitis $\mathrm{C}$ infection. ${ }^{91}$ In contrast, no fibrosis was seen in 12 subjects treated with deferoxamine, five of whom were hepatitis $\mathrm{C}$ seropositive. ${ }^{91}$ The contribution of deferiprone to the development of fibrosis in these patients is difficult to decipher given that the majority of subjects who developed fibrosis had concomitant hepatitis $\mathrm{C}$ infection, which can cause hepatic fibrosis itself. Furthermore, the effect of deferiprone on hepatic fibrosis has not been confirmed in follow-up studies. ${ }^{101,102}$ In the largest study to date, no significant progression of fibrosis was observed in 56 patients
(11 seropositive for hepatitis C) with liver biopsy specimens obtained before and after treatment with deferiprone at a mean interval of 3.1 years. ${ }^{102}$

\section{Adherence}

In a review of studies assessing adherence with treatment with deferiprone, overall compliance ranged from $79 \%$ to $96 \% .{ }^{69}$ In these studies, adherence was monitored by pill counts, patient report, physician assessment, and/or medication event monitoring system. Similarly, comparative studies of adherence with deferoxamine versus deferiprone suggest overall better compliance with the oral chelator. ${ }^{69}$

\section{Deferasirox}

\section{Pharmacology}

Deferasirox is the first oral iron chelator approved for use in the USA, and it has also been approved in a number of other countries (Table 3). Deferasirox, a triazole compound, was designed using computer-aided molecular modeling. ${ }^{103}$ Deferasirox binds iron in a 2:1 ratio (tridentate chelator). The drug has a high specificity for iron, with minimal binding to copper and zinc. Deferasirox is supplied as orally dispersible tablets that are dissolved in water or juice and should be administered on an empty stomach at least $1 / 2$ hour before a meal. ${ }^{104}$ Deferasirox is rapidly absorbed, achieving peak plasma levels within 1-3 hours after administration. Its half-life ranges from 7 to 16 hours, ${ }^{34}$ and is longer with higher doses, ${ }^{103}$ supporting a once-daily dosing regimen. The deferasirox-iron complex is excreted almost exclusively in the feces, with minimal urinary excretion. ${ }^{103}$ Mean iron excretion was $0.3 \mathrm{mg} / \mathrm{kg} /$ day with a deferasirox dose of $20 \mathrm{mg} / \mathrm{kg}$ and rose to $0.5 \mathrm{mg} / \mathrm{kg} /$ day with a $40 \mathrm{mg} / \mathrm{kg}$ dose. ${ }^{105}$

\section{Efficacy}

\section{Hepatic iron and ferritin levels}

Deferasirox in doses of $20-30 \mathrm{mg} / \mathrm{kg}$ /day was shown to have similar efficacy to deferoxamine with regard to reduction in liver iron concentration and serum ferritin levels in a randomized trial of 586 patients with thalassemia major. ${ }^{19}$ In that trial, four different dose levels of deferasirox were tested $(5,10,20$, and $30 \mathrm{mg} / \mathrm{kg})$, with initial dosing determined according to baseline liver iron concentration (lower doses for lower liver iron concentrations). A similar dosing algorithm was utilized for deferoxamine in that study, but subjects were allowed to remain on their prestudy deferoxamine dose, which resulted in proportionately higher deferoxamine than deferasirox 
doses in the lowest two liver iron concentration groups. The primary objective of noninferiority of deferasirox to deferoxamine across all treatment groups was not attained, which was probably related to this relative underdosing of deferasirox in the lowest two dose groups. However, noninferiority of deferasirox was demonstrated at the 20 and $30 \mathrm{mg} / \mathrm{kg}$ dose groups. The average reduction in liver iron concentration over the 1-year treatment period with deferasirox at 20 or $30 \mathrm{mg} / \mathrm{kg}$ was $5.3 \pm 8.0 \mathrm{mg} / \mathrm{g} \mathrm{dw}$, compared with a reduction of $4.3 \pm 5.8 \mathrm{mg} / \mathrm{g} \mathrm{dw}$ with deferoxamine, $P=0.367 .{ }^{19}$ Trends in serum ferritin levels over the course of the study paralleled the changes in liver iron concentration.

Phase II studies in patients with other transfusiondependent anemias have demonstrated similar results. In a multicenter study, 195 patients with sickle cell disease were randomized to receive deferasirox (10-30 mg/kg/day) or deferoxamine (20 to $\geq 50 \mathrm{mg} / \mathrm{kg}, 5$ days per week) with dosing based on the pretreatment liver iron content. ${ }^{20} \mathrm{~A}$ mean reduction in liver iron concentration of $3 \mathrm{mg} / \mathrm{g} \mathrm{dw}$, was seen after 1 year of treatment with deferasirox, comparable to the decrease in liver iron concentration seen with deferoxamine $(2.8 \mathrm{mg} / \mathrm{g} \mathrm{dw})$. Similarly, an overall significant reduction in liver iron concentration was seen in a Phase II study of 184 patients with myelodysplasia, thalassemia, Diamond-Blackfan anemia, and other rare transfusiondependent anemias, in patients who received deferasirox at $20-30 \mathrm{mg} / \mathrm{kg}$ for a period of 1 year. $^{2}$

Subsequent analyses have shown that the response to deferasirox is dependent on ongoing tranfusional requirements. For most patients with transfusional iron intake averaging $<0.3 \mathrm{mg} / \mathrm{kg} / \mathrm{day}$, a dose of $20 \mathrm{mg} / \mathrm{kg}$ of deferasirox was effective in reducing liver iron concentration, while in over $50 \%$ of patients with the highest iron intake of $>0.5 \mathrm{mg} / \mathrm{kg} / \mathrm{day}$, the dose of $20 \mathrm{mg} / \mathrm{kg} /$ day did not reduce liver iron concentration effectively. ${ }^{1}$ In addition to ongoing transfusional iron intake, individual variability in drug pharmacokinetics may impact response to deferasirox. ${ }^{106}$ Both of these factors might be addressed by using higher doses of the drug. A subanalysis of 264 subjects treated with deferasirox at doses $>30 \mathrm{mg} / \mathrm{kg} /$ day for a median duration of 36 months demonstrated a reduction in serum ferritin levels without increased toxicity. ${ }^{107}$ Currently, doses of deferasirox of up to $40 \mathrm{mg} / \mathrm{kg} /$ day are approved for use. Dosing of deferasirox should be guided by the goal of maintenance or reduction of body iron stores, ongoing transfusional requirements, and trends in ferritin and liver iron content during treatment.

\section{Cardiac iron removal}

Early clinical data suggest that deferasirox is able to remove cardiac iron. In a prospective study of 114 patients with thalassemia and evidence of cardiac iron loading (cardiac T2* values of 5 to $<20 \mathrm{~ms}$ ) but normal left ventricular function, cardiac T2* significantly improved from a mean of 11.2 to $12.9 \mathrm{~ms}$ after 12 months of treatment with deferasirox at a mean dose of $32.6 \mathrm{mg} / \mathrm{kg} /$ day. ${ }^{108} \mathrm{~A}$ further improvement in cardiac $\mathrm{T} 2 *$ to $14.8 \mathrm{~ms}$ was seen with an additional year of treatment at a mean dose of $36.1 \mathrm{mg} / \mathrm{kg} /$ day. ${ }^{109}$ A concomitant significant reduction in serum ferritin levels and liver iron concentration was demonstrated. Interestingly, there was no significant improvement in left ventricular ejection fraction (LVEF) over the 2 years of study, although the ejection fraction was normal at baseline. ${ }^{109}$ Nonetheless, significant improvement in LVEF has been demonstrated with deferiprone in a group of patients with a similar degree of cardiac iron loading and normal baseline LVEF, ${ }^{92}$ suggesting that deferiprone may cause a more rapid improvement in cardiac function than deferasirox. In a second study of 27 patients with thalassemia and cardiac T2 $* 20 \mathrm{~ms}$ with LVEF of $56 \%$ or higher, cardiac iron measurements improved by $16 \%(P=0.06)$ following 18 months of treatment with deferasirox (mean ending dose of $33.3 \mathrm{mg} / \mathrm{kg} /$ day). ${ }^{110}$ However, cardiac T2* worsened in about $50 \%$ of these patients and this failure to respond was predicted by higher baseline liver iron concentration and ferritin levels. ${ }^{110}$ Similar to the previous study, no change in LVEF was seen over the 18 months of treatment. A third study of 19 patients with beta thalassemia and iron overload also demonstrated improvement in cardiac T2* over 18 months of treatment (17.2 to $21.5 \mathrm{~ms}$ ). ${ }^{111}$ Administration of deferasirox (mean dose $27.6 \mathrm{mg} / \mathrm{kg} /$ day) also can prevent cardiac iron accumulation; in 78 patients with thalassemia without evidence of cardiac iron loading (cardiac T2* $\geq 20 \mathrm{~ms}$ ), cardiac T2* did not worsen over a year of treatment (32 to $32.5 \mathrm{~ms}) \cdot{ }^{108}$ Moreover, in that study, no subjects with normal cardiac $\mathrm{T} 2 *$ at baseline developed an abnormal study (T2* $<20 \mathrm{~ms}$ ) over the follow-up period.

The ability of deferasirox to reverse cardiac disease has not yet been investigated, as the prior studies all required normal left ventricular function for inclusion. A case report of a 15-year-old boy with beta thalassemia and congestive heart failure showed improvement in LVEF from 33\% to $58 \%$ with 15 months of treatment with deferasirox at $30 \mathrm{mg} / \mathrm{kg} /$ day $^{112}$ and a second report showed normalization of LVEF following 3 years of treatment with deferasirox in a 22-year-old woman with severe aplastic anemia and 
iron-related cardiac dysfunction (initial LVEF of 26.5\%). ${ }^{113}$ Before a recommendation can be made regarding the use of deferasirox to treat patients with iron-related cardiac disease, prospective studies are needed that assess the rapidity and degree of cardiac iron removal, improvement in left ventricular function, and ability to reverse iron-related cardiac complications with deferasirox compared with other chelators.

\section{Adverse effects}

The toxicity profile of deferasirox generally is similar across disease states. ${ }^{2,19,20}$ Gastrointestinal disturbances, including nausea, vomiting, and abdominal pain are common. ${ }^{19}$ Although usually transient and dose related, these symptoms have led to discontinuation of the drug in some patients. The gastrointestinal side effects may be related to lactose intolerance in some patients because lactose is present in the drug preparation. ${ }^{20}$ Diffuse, maculopapular skin rashes that usually resolve even if the drug is continued, have been reported in approximately $10 \%$ of subjects receiving deferasirox. ${ }^{19,20,33}$ Nephrotoxicity also can be seen with use of the drug. Approximately $33 \%$ of patients experience mild elevations in serum creatinine levels, although few patients have experienced elevations beyond the normal range. ${ }^{19,20}$ Rare reports of renal impairment and renal failure with deferasirox use have led to a black box warning about this side effect. Intermittent proteinuria has also been seen with the administration of the drug. ${ }^{19}$ Fanconi syndrome, a proximal renal tubular dysfunction leading to electrolyte abnormalities, has been reported in a several patients taking deferasirox, sometimes in the setting of acute illness; this toxicity resolved after discontinuation of the drug and recurred in some patients with reinstitution of the drug. ${ }^{114-116}$ Elevations in hepatic transaminases to more than five times baseline values also have been reported. ${ }^{19,20}$ Fulminant hepatic failure has also been reported in rare cases, often in patients with comorbidities. Gastrointestinal bleeding also has been reported rarely with deferasirox use. Although more common in older patients with significant comorbidities, this toxicity has been reported in children as well. ${ }^{117}$ Cataracts or lenticular opacities and audiotoxicity were reported at low rates, similar to deferoxamine. ${ }^{19,20}$ Importantly, agranulocytosis has not been seen with deferasirox administration and the rare reports of neutropenia with deferasirox were thought unlikely to be drug related but rather related to the underlying hematological disorder.

\section{Adherence}

Adherence with deferasirox therapy has been reported to be better than with deferoxamine. ${ }^{118}$ Similarly, patients reported greater satisfaction and convenience with deferasirox in comparison with deferoxamine. ${ }^{119}$ In a preliminary report of patients participating in the Thalassemia Clinical Research Network comprised of subjects living in North America and London, UK, deferasirox was the most commonly used chelator at the time of enrollment (2007-2009), being taken by $57 \%$ of patients on chelation. ${ }^{118}$

\section{Combination chelation therapy Deferiprone and deferoxamine}

The most extensively studied combination chelation therapy is that of deferiprone and deferoxamine. A variety of dosing regimens have been utilized ${ }^{82,120,121}$ and iron balance studies have shown an additive effect when the two drugs are administered together. A significant reduction in serum ferritin levels was shown with combination therapy. ${ }^{120,121}$ Most important, the combination of deferoxamine and deferiprone appears to be particularly efficacious for cardiac iron removal and treatment of iron-related cardiac disease. A shuttling hypothesis, whereby deferiprone, a smaller molecule, enters cardiac cells, binds iron, and then transfers it to deferoxamine for excretion has been proposed. ${ }^{122,123}$ Significant reduction in cardiac iron stores measured by MRI, ${ }^{121}$ and significant improvement in left ventricular shortening fraction ${ }^{120,121}$ have been reported using combination therapy, without unexpected toxicities.

The largest randomized placebo-controlled clinical trial compared the use of deferoxamine alone or in combination with deferiprone in the treatment of 65 patients with mild to moderate cardiac iron loading (cardiac T2* 8-20 ms). ${ }^{124}$ The beneficial effect of combined therapy on cardiac iron removal and improvement in cardiac function was confirmed. After a 12-month treatment period, those receiving combination therapy had significantly greater improvement in cardiac T2* (from 11.7 to $17.7 \mathrm{~ms}$ compared with 12.4 to $15.7 \mathrm{~ms}$ ) and in LVEF (2.6\% compared with $0.6 \%$ ) than those receiving deferoxamine alone. Furthermore, in a single arm trial of 15 patients with severe myocardial siderosis $(\mathrm{T} 2 *<8 \mathrm{~ms})$ and myocardial dysfunction, treatment with deferoxamine (mean dose $38 \pm 10.2 \mathrm{mg} / \mathrm{kg}$ for 5.3 days/week) combined with deferiprone $(73.9 \pm 4 \mathrm{mg} / \mathrm{kg} /$ day $)$ resulted in significant improvement in cardiac T2* (5.7 to $7.9 \mathrm{~ms}$ ) and LVEF $(51.2 \%$ to $65.6 \%$ ) as well as a reduction in serum ferritin and liver iron concentration. ${ }^{125}$ A second, smaller, prospective study of combination therapy with deferoxamine and deferiprone compared with deferoxamine monotherapy for patients with established cardiac disease showed a significantly lower rate of cardiac events in heavily iron-loaded patients treated 
with combined therapy (no events among nine subjects) compared with monotherapy (four cardiac events with three deaths among five subjects). ${ }^{126}$ Similarly, prospective and retrospective analyses have supported that the combination of deferoxamine and deferiprone is superior to other chelators in reducing cardiac iron in clinical practice. ${ }^{97,127}$

\section{Deferasirox and deferoxamine}

Limited data, consisting mostly of animal studies, small case series, and pilot studies, exist regarding treatment with deferasirox combined with deferoxamine. In an ironoverloaded gerbil model, the addition of deferoxamine to deferasirox did not cause any detectable increase in organ toxicity above treatment with deferasirox alone. ${ }^{128}$ However, in that study, combination treatment with deferasirox and deferoxamine did not show additive iron excretion, suggesting that the chelators may simply compete for a common iron pool. ${ }^{128}$ It is unclear if this will hold true in humans but sequential (administered on different days) rather than combination (administered on the same day) therapy would be expected to be a better strategy if the two chelators simply compete for a common iron pool. Such an approach could limit toxicity associated with each chelator and improve adherence.

Limited information is available regarding the use of sequential or combined therapy with deferoxamine and deferasirox in humans. In a retrospective study, seven patients with thalassemia and iron overload were treated with deferasirox (20-30 mg/kg/day) for 4 consecutive days followed by deferoxamine $(20-40 \mathrm{mg} / \mathrm{kg} /$ day, subcutaneously over 8-12 hours) for 3 days with median treatment duration of 25 months (range 8-32 months). ${ }^{129}$ A significant reduction in serum ferritin levels was evidenced and no patients experienced significant toxicity. In addition, overall costs were reduced because deferasirox was significantly more expensive than deferoxamine, even including the supplies needed for administration.

In a second preliminary report, 14 subjects with transfusion-dependent thalassemia with severe iron overload and/or evidence of organ dysfunction were treated prospectively with deferoxamine $(35-50 \mathrm{mg} / \mathrm{kg} /$ day for 3-7 days/ week) and deferasirox (20-30 mg/kg daily, 7 days/week). ${ }^{130}$ In contrast to the previous report, the two drugs were given on the same days, rather than sequentially. After 26 weeks of combined therapy, a significant reduction in liver iron concentration from 12 to $10.6 \mathrm{mg} / \mathrm{g} \mathrm{dw}$ was seen, but there was no significant change in myocardial T2*, ejection fraction, or serum ferritin. It remains to be seen whether these parameters will improve with longer follow-up. One subject died from sepsis and one interrupted drug treatment secondary to abdominal pain, but no elevations in serum creatinine or ALT were seen. Additional safety and efficacy data are needed before clinical recommendations for the combination of deferasirox/deferoxamine can be made.

\section{Deferasirox and deferiprone}

Combination therapy with deferasirox and deferiprone would be particularly desirable, as it would avoid the use of parenteral therapy; however, data regarding such therapy are lacking. In one report, two subjects who experienced significant toxicity during monotherapy with each chelator (deferoxamine, deferiprone, and deferasirox) individually were treated with deferasirox $(30 \mathrm{mg} / \mathrm{kg} /$ day $)$ alternating with deferiprone $(75-85 \mathrm{mg} / \mathrm{kg} /$ day $) .{ }^{131}$ The toxicities experienced with monotherapy were not evidenced and iron burden improved or remained well controlled. In a second report, three subjects with severe cardiac iron loading ( $2 *<6 \mathrm{~ms}$ ) were treated with deferasirox $(20-40 \mathrm{mg} / \mathrm{kg} /$ day) and deferiprone $(75-100 \mathrm{mg} / \mathrm{kg} /$ day) for 7 days/week. ${ }^{132}$ After a treatment duration of 7-28 months, a significant improvement in cardiac $\mathrm{T} 2 *$ was evidenced, but with worsening of liver iron concentration in one, and minimal to no improvement in the other two subjects. Adverse events included gastrointestinal upset and fluctuating transaminase levels, but renal dysfunction and neutropenia were not seen. Prospective studies are needed to determine the optimal dosing regimen, efficacy, and safety of this treatment approach.

\section{Other oral chelators in development} FBS0701 is a new oral chelator that has undergone Phase I testing in patients with transfusion-dependent anemias. ${ }^{133}$ The drug is a desferrithiocin derivative that has been modified to minimize nephrotoxicity. It binds iron in a ratio of two molecules of drug to one molecule of iron (tridentate). In a Phase Ib dose escalation study, FBS0701 was administered for a total of 7 days to patients with transfusion-dependent anemias; four different dose levels were tested $(3,8,16$, and $32 \mathrm{mg} / \mathrm{kg}$ ). ${ }^{133}$ The mean half-life was $16.2-21.3$ hours, supportive of daily dosing. Adverse effects were rare and included urinary discoloration, headache, and gastrointestinal symptoms. One patient with sickle cell disease experienced a mild prolongation of the QTc on electrocardiogram, which was not clearly drug-related. One serious adverse event, hospitalization for vaso-occlusive pain, occurred in a patient with sickle cell disease, also thought to be unrelated to the 
drug. Further studies are needed to determine the effect of FBS0701 on iron removal and a Phase II trial is ongoing.

\section{Conclusion}

Three iron chelators, deferoxamine, deferiprone, and deferasirox, have undergone extensive study and are in clinical use worldwide, although deferiprone is not currently approved for use in North America. Individual properties of the chelators, including efficacy at both cardiac and liver iron removal, adverse-effect profile, tolerability, and patient preference should be considered in tailoring an individual's chelation regimen. Trends in liver and cardiac iron burden and ongoing transfusional iron intake should be utilized to adjust the dosing of the chelator. Combination therapy with deferiprone and deferoxamine has been shown to be the most efficacious with regard to improvement in cardiac function and cardiac iron removal. Other chelator combinations require further study before routine clinical use can be recommended.

\section{Disclosure}

The author reports no conflicts of interest in this work.

\section{References}

1. Cohen AR, Glimm E, Porter JB. Effect of transfusional iron intake on response to chelation therapy in \{beta $\}$-thalassemia major. Blood. 2008; 111(2):583-587.

2. Porter J, Galanello R, Saglio G, et al. Relative response of patients with myelodysplastic syndromes and other transfusion-dependent anaemias to deferasirox (ICL670): a 1-year prospective study. Eur J Haematol. 2008;80(2):168-176.

3. Bridle KR, Frazer DM, Wilkins SJ, et al. Disrupted hepcidin regulation in HFE-associated haemochromatosis and the liver as a regulator of body iron homoeostasis. Lancet. 2003;361(9358):669-673.

4. Allen KJ, Gurrin LC, Constantine CC, et al. Iron-overload-related disease in HFE hereditary hemochromatosis. $N$ Engl J Med. 2008; 358(3):221-230.

5. Phatak P, Brissot P, Wurster M, et al. A phase $1 / 2$, dose-escalation trial of deferasirox for the treatment of iron overload in HFE-related hereditary hemochromatosis. Hepatology. 2010;52(5):1671-1779.

6. Finkenstedt A, Bianchi P, Theurl I, et al. Regulation of iron metabolism through GDF15 and hepcidin in pyruvate kinase deficiency. $\mathrm{Br} J$ Haematol. 2009;144(5):789-793.

7. Tanno T, Bhanu NV, Oneal PA, et al. High levels of GDF15 in thalassemia suppress expression of the iron regulatory protein hepcidin. Nat Med. 2007;13(9):1096-1101.

8. Akrawinthawong K, Chaowalit N, Chatuparisuth T, Siritanaratkul N. Effectiveness of deferiprone in transfusion-independent beta-thalassemia/ HbE patients. Hematology. 2011;16(2):113-122.

9. Deeren D. Deferasirox in pyruvate kinase deficiency. Ann Hematol. 2009;88(4):397.

10. Ladis V, Berdousi H, Gotsis E, Kattamis A. Deferasirox administration for the treatment of non-transfusional iron overload in patients with thalassaemia intermedia. Br J Haematol. 2010;151(5):504-508.

11. Voskaridou E, Plata E, Douskou M, et al. Treatment with deferasirox (Exjade) effectively decreases iron burden in patients with thalassaemia intermedia: results of a pilot study. Br J Haematol. 2009;148(2): $332-334$.
12. Breuer W, Hershko C, Cabantchik ZI. The importance of non-transferrin bound iron in disorders of iron metabolism. Transfus Sci. 2000;23(3): 185-192.

13. Zurlo MG, De Stefano P, Borgna-Pignatti C, et al. Survival and causes of death in thalassaemia major. Lancet. 1989;2:27-30.

14. Jean G, Terzoli S, Mauri R, et al. Cirrhosis associated with multiple transfusions in thalassaemia. Arch Dis Child. 1984;59(1):67-70.

15. Borgna-Pignatti C, De Stefano P, Zonta L, et al. Growth and sexual maturation in thalassemia major. J Pediatr. 1985;106(1):150-155.

16. Cunningham MJ, Macklin EA, Neufeld EJ, Cohen AR. Complications of beta-thalassemia major in North America. Blood. 2004;104(1): 34-39.

17. Thuret I, Pondarre C, Loundou A, et al. Complications and treatment of patients with beta-thalassemia in France: results of the National Registry. Haematologica. 2010;95(5):724-729.

18. Brittenham GM, Cohen AR, McLaren CE, et al. Hepatic iron stores and plasma ferritin concentration in patients with sickle cell anemia and thalassemia major. Am J Hematol. 1993;42(1):81-85.

19. Cappellini MD, Cohen A, Piga A, et al. A phase 3 study of deferasirox (ICL670), a once-daily oral iron chelator, in patients with beta-thalassemia. Blood. 2006;107(9):3455-3462.

20. Vichinsky E, Onyekwere O, Porter J, et al. A randomised comparison of deferasirox versus deferoxamine for the treatment of transfusional iron overload in sickle cell disease. Br J Haematol. 2007;136(3):501-508.

21. Olivieri NF, Nathan DG, MacMillan JH, et al. Survival in medically treated patients with homozygous beta-thalassemia. $N$ Engl J Med. 1994;331(9):574-578.

22. Telfer PT, Prestcott E, Holden S, Walker M, Hoffbrand AV, Wonke B. Hepatic iron concentration combined with long-term monitoring of serum ferritin to predict complications of iron overload in thalassaemia major. Br J Haematol. 2000;110:971-977.

23. Files B, Brambilla D, Kutlar A, et al. Longitudinal changes in ferritin during chronic transfusion: a report from the Stroke Prevention Trial in Sickle Cell Anemia (STOP). J Pediatr Hematol Oncol. 2002;24(4): 284-290.

24. Adamkiewicz TV, Abboud MR, Paley C, et al. Serum ferritin level changes in children with sickle cell disease on chronic blood transfusion are nonlinear and are associated with iron load and liver injury. Blood. 2009;114(21):4632-4638.

25. Pakbaz Z, Fischer R, Fung E, Nielsen P, Harmatz P, Vichinsky E. Serum ferritin underestimates liver iron concentration in transfusion independent thalassemia patients as compared to regularly transfused thalassemia and sickle cell patients. Pediatr Blood Cancer. 2007;49(3): 329-332.

26. Angelucci E, Brittenham GM, McLaren CE, et al. Hepatic iron concentration and total body iron stores in thalassemia major. $N$ Engl J Med. 2000;343(5):327-331.

27. Cartwright GE, Edwards CQ, Kravitz K, et al. Hereditary hemochromatosis. Phenotypic expression of the disease. N Engl J Med. 1979; 301(4):175-179.

28. Farmaki K, Tzoumari I, Pappa C, Chouliaras G, Berdoukas V. Normalisation of total body iron load with very intensive combined chelation reverses cardiac and endocrine complications of thalassaemia major. Br J Haematol. 2009;148(3):466-475.

29. Anderson LJ, Holden S, Davis B, et al. Cardiovascular T2-star (T2*) magnetic resonance for the early diagnosis of myocardial iron overload. Eur Heart J. 2001;22(23):2171-2179.

30. Chirnomas DS, Geukes-Foppen M, Barry K, et al. Practical implications of liver and heart iron load assessment by T2*-MRI in children and adults with transfusion-dependent anemias. Am J Hematol. 2008; 83(10):781-783.

31. Villeneuve JP, Bilodeau M, Lepage R, Cote J, Lefebvre M. Variability in hepatic iron concentration measurement from needle-biopsy specimens. J Hepatol. 1996;25(2):172-177.

32. Brittenham GM, Farrell DE, Harris JW, et al. Magnetic-susceptibility measurement of human iron stores. N Engl J Med. 1982;307: $1671-1675$. 
33. Galanello R, Piga A, Forni GL, et al. Phase II clinical evaluation of deferasirox, a once-daily oral chelating agent, in pediatric patients with beta-thalassemia major. Haematologica. 2006;91(10):1343-1351.

34. Piga A, Galanello R, Forni GL, et al. Randomized phase II trial of deferasirox (Exjade, ICL670), a once-daily, orally-administered iron chelator, in comparison to deferoxamine in thalassemia patients with transfusional iron overload. Haematologica. 2006;91(7):873-880.

35. Olivieri NF, Brittenham GM, Matsui D, et al. Iron-chelation therapy with oral deferiprone in patients with thalassemia major. NEngl J Med. 1995;332:918-922.

36. Nielsen P, Engelhardt R, Grosse R, Janka G, Harmatz P, Fischer R. Italian Society of Hematology guidelines for thalassemia and noninvasive iron measurements. Haematologica. 2009;94(2):294-295; author reply 295-296.

37. Brittenham GM, Badman DG. Noninvasive measurement of iron: report of an NIDDK workshop. Blood. 2003;101(1):15-19.

38. Wood JC. Magnetic resonance imaging measurement of iron overload. Curr Opin Hematol. 2007;14(3):183-190.

39. St Pierre TG, Clark PR, Chua-anusorn W, et al. Noninvasive measurement and imaging of liver iron concentrations using proton magnetic resonance. Blood. 2005;105(2):855-861.

40. Westwood MA, Wonke B, Maceira AM, et al. Left ventricular diastolic function compared with $\mathrm{T} 2 *$ cardiovascular magnetic resonance for early detection of myocardial iron overload in thalassemia major J Magn Reson Imaging. 2005;22(2):229-233.

41. Wood JC, Enriquez C, Ghugre N, et al. MRI R2 and R2* mapping accurately estimates hepatic iron concentration in transfusion-dependent thalassemia and sickle cell disease patients. Blood. 2005;106(4): 1460-1465.

42. Kirk P, Roughton M, Porter JB, et al. Cardiac T2* magnetic resonance for prediction of cardiac complications in thalassemia major. Circulation. 2009;120(20):1961-1968.

43. Fung EB, Harmatz PR, Lee PD, et al. Increased prevalence of ironoverload associated endocrinopathy in thalassaemia versus sickle-cell disease. Br J Haematol. 2006;135(4):574-582.

44. Wood JC, Tyszka M, Carson S, Nelson MD, Coates TD. Myocardial iron loading in transfusion-dependent thalassemia and sickle cell disease. Blood. 2004;103:1934-1936.

45. Roggero S, Quarello P, Vinciguerra T, Longo F, Piga A, Ramenghi U. Severe iron overload in Blackfan-Diamond anemia: a case-control study. Am J Hematol. 2009;84(11):729-732.

46. Fung EB, Harmatz P, Milet M, et al. Morbidity and mortality in chronically transfused subjects with thalassemia and sickle cell disease: A report from the multi-center study of iron overload. Am J Hematol. 2007;82(4):255-265.

47. Noetzli LJ, Coates TD, Wood JC. Pancreatic iron loading in chronically transfused sickle cell disease is lower than in thalassaemia major. $\mathrm{Br} J$ Haematol. 2011;152(2):229-233.

48. Anderson LJ, Westwood MA, Holden S, et al. Myocardial iron clearance during reversal of siderotic cardiomyopathy with intravenous desferrioxamine: a prospective study using $\mathrm{T} 2 *$ cardiovascular magnetic resonance. Br J Haematol. 2004;127(3):348-355.

49. Brittenham GM, Griffith PM, Nienhuis AW, et al. Efficacy of deferoxamine in preventing complications of iron overload in patients with thalassemia major. $N$ Engl J Med. 1994;331(9):567-573.

50. Lee P, Mohammed N, Marshall L, et al. Intravenous infusion pharmacokinetics of desferrioxamine in thalassaemic patients. Drug Metab Dispos. 1993;21(4):640-644.

51. Cohen AR, Mizanin J, Schwartz E. Rapid removal of excessive iron with daily, high-dose intravenous chelation therapy. Journal of Pediatrics. 1989;115(1):151-155.

52. Freedman MH, Grisaru D, Oliveri N, MacLusky I, Thorner PS. Pulmonary syndrome in patients with thalassemia major receiving intravenous deferoxamine infusions. Am J Dis Child. 1990;144(5):565-569.

53. Levine JE, Cohen A, MacQueen M, Martin M, Giardina PJ. Sensorimotor neurotoxicity associated with high-dose deferoxamine treatment. J Pediatr Hematol Oncol. 1997;19(2):139-141.
54. Franchini M, Gandini G, de Gironcoli M, Vassanelli A, BorgnaPignatti C, Aprili G. Safety and efficacy of subcutaneous bolus injection of deferoxamine in adult patients with iron overload. Blood. 2000;95(9): 2776-2779.

55. Franchini M, Gandini G, Veneri D, Aprili G. Safety and efficacy of subcutaneous bolus injection of deferoxamine in adult patients with iron overload: an update. Blood. 2004;103(2):747-748.

56. Pippard MJ, Letsky EA, Callender ST, Weatherall DJ. Prevention of iron loading in transfusion-dependent thalassaemia. Lancet. 1978;1(8075): 1178-1181.

57. Nienhuis A. Vitamin C and Iron. N Engl J Med. 1981;304(3): $170-171$.

58. Taher A, Sheikh-Taha M, Koussa S, Inati A, Neeman R, Mourad F. Comparison between deferoxamine and deferiprone (L1) in iron-loaded thalassemia patients. Eur J Haematol. 2001;67(1):30-34.

59. Wolfe L, Oliveri N, Sallan D, et al. Prevention of cardiac disease by sucutaneous deferoxamine in patients with thalassemia major. $N$ Engl J Med. 1985;312(25):1600-1603.

60. De Sanctis V, Eleftheriou A, Malaventura C. Prevalence of endocrine complications and short stature in patients with thalassaemia major: a multicenter study by the Thalassaemia International Federation (TIF). Pediatr Endocrinol Rev. 2004;2 Suppl 2:249-255.

61. Barry M, Flynn DM, Letsky EA, Risdon RA. Long-term chelation therapy in thalassaemia major: effect on liver iron concentration, liver histology, and clinical progress. Br Med J. 1974;2(5909):16-20.

62. Cohen A, Martin M, Schwartz E. Depletion of excessive liver iron stores with desferrioxamine. Br J Haematol. 1984;58:369-373.

63. Davis BA, Porter JB. Long-term outcome of continuous 24-hour deferoxamine infusion via indwelling intravenous catheters in high-risk beta-thalassemia. Blood. 2000;95(4):1229-1236.

64. Olivieri NF, Buncic JR, Chew E, et al. Visual and auditory neurotoxicity in patients receiving subcutaneous deferoxamine infusions. $N \mathrm{Engl}$ J Med. 1986;314(14):869-873.

65. De Sanctis V, Pinamonti A, DiPalma A, et al. Growth and development in thalassemia major patients with severe bone lesions due to desferrioxamine. Eur J Pediatr. 1996;155(5):368-372.

66. Porter JB, Jaswon MS, Huehns ER, East CA, Hazell JW. Desferrioxamine ototoxicity: evaluation of risk factors in thalassaemic patients and guidelines for safe dosage. Br J Haematol. 1989;73(3) 403-409.

67. Adamkiewicz TV, Berkovitch M, Krishnan C, Polsinelli C, Kermack D, Olivieri NF. Infection due to Yersinia enterocolitica in a series of patients with beta-thalassemia: incidence and predisposing factors. Clin Infect Dis. 1998;27(6):1362-1366

68. Chan GC, Chan S, Ho PL, Ha SY. Effects of chelators (deferoxamine, deferiprone and deferasirox) on the growth of Klebsiella pneumoniae and Aeromonas hydrophila isolated from transfusion-dependent thalassemia patients. Hemoglobin. 2009;33(5):352-360.

69. Delea TE, Edelsberg J, Sofrygin O, et al. Consequences and costs of noncompliance with iron chelation therapy in patients with transfusiondependent thalassemia: a literature review. Transfusion. 2007;47(10): 1919-1929.

70. Ward A, Caro JJ, Green TC, et al. An international survey of patients with thalassemia major and their views about sustaining life-long desferrioxamine use. BMC Clin Pharmacol. 2002;2:3.

71. Beratis S. Noncompliance with iron chelation therapy in patients with beta thalassaemia. J Psychosom Res. 1989;33(6):739-745.

72. Borgna-Pignatti C, Rugolotto S, DeStefano P, et al. Survival and disease complications in thalassemia major. Ann N Y Acad Sci. 1998;850: 227-231.

73. Ceci A, Baiardi P, Catapano M, et al. Risk factors for death in patients with beta-thalassemia major: results of a case-control study. Haematologica. 2006;91(10):1420-1421.

74. Kontoghiorghes GJ, Pattichis K, Neocleous K, Kolnagou A. The design and development of deferiprone (L1) and other iron chelators for clinical use: targeting methods and application prospects. Curr Med Chem. 2004;11(16):2161-2183. 
75. Al-Refaie FN, Sheppard LN, Nortey P, Wonke B, Hoffbrand AV. Pharmacokinetics of the oral iron chelator deferiprone (L1) in patients with iron overload. Br J Haematol. 1995;89:403-408.

76. Matsui D, Klein J, Hermann C. Relationship between the pharmacokinetics and iron excretion of the new oral iron chelator 1,2-dimethyl-3hydroxypyrid-4-1 in patients with thalassemia. Clin Pharmacol Ther. 1991;50(3):294-298.

77. El Alfy M, Sari TT, Lee CL, Tricta F, El-Beshlawy A. The safety, tolerability, and efficacy of a liquid formulation of deferiprone in young children with transfusional iron overload. J Pediatr Hematol Oncol. 2010;32(8):601-605.

78. Collins AF, Fassos FF, Stobie S, et al. Iron-balance and dose-response studies of the oral iron chelator 1,2-dimethyl-3-hydroxypyrid-4-one (L1) in iron-loaded patients with sickle cell disease. Blood. 1994;83(8): 2329-2333.

79. Olivieri NF, Koren G, Hermann C, et al. Comparison of oral iron chelator L1 and desferrioxamine in iron-loaded patients. Lancet. 1990; 336(8726):1275-1279.

80. Agarwal MB, Gupte SS, Viswanathan C, et al. Long-term assessment of efficacy and safety of L1, an oral iron chelator, in transfusion dependent thalassaemia: Indian trial. Br J Haematol. 1992;82(2): 460-466.

81. Al-Refaie FN, Wonke B, Hoffbrand AV, Wickens DG, Nortey P, Kontoghiorges GJ. Efficacy and possible adverse effects of the oral iron chelator 1,2-dimethyl-3-hydroxypyrid-4-one (L1) in thalassemia major. Blood. 1992;80(3):593-599.

82. Wonke B, Wright $C$, Hoffbrand AV. Combined therapy with deferiprone and desferrioxamine. Br J Haematol. 1998;103:361-364.

83. Kersten MJ, Lange R, Smeets ME, et al. Long-term treatment of transfusional iron overload with the oral iron chelator deferiprone (L1): a Dutch multicenter trial. Ann Hematol. 1996;73(5): 247-252.

84. Maggio A, D'Amico G, Morabito A, et al. Deferiprone versus deferoxamine in patients with thalassemia major: a randomized clinical trial. Blood Cells Mol Dis. 2002;28(2):196-208.

85. Al-Refaie FN, Hershko C, Hoffbrand AV, et al. Results of long-term deferiprone (L1) therapy: a report by the International Study Group on oral iron chelators. Br J Haematol. 1995;91(1):224-229.

86. Ceci A, Baiardi P, Felisi M, et al. The safety and effectiveness of deferiprone in a large-scale, 3-year study in Italian patients. $\mathrm{Br} J$ Haematol. 2002;118(1):330-336.

87. Cohen AR, Galanello R, Piga A, DiPalma A, Vullo C, Tricta F. Safety profile of the oral iron chelator deferiprone: a multicentre study. $\mathrm{Br} \mathrm{J}$ Haematol. 2000;108(2):305-312.

88. Hoffbrand AV, Al-Refaie F, Davis B, et al. Long-term trial of deferiprone in 51 transfusion-dependent iron overloaded patients. Blood. 1998;91(1):295-300.

89. Cohen AR, Galanello R, Piga A, DeSanctis V, Tricta F. Safety and effectiveness of long-term therapy with the oral iron chelator deferiprone. Blood. 2003;102(5):1583-1587.

90. Mazza P, Amurri B, Lazzari G, et al. Oral iron chelating therapy. A single center interim report on deferiprone (L1) in thalassemia. Haematologica. 1998;83(6):496-501.

91. Olivieri NF, Brittenham GM, McLaren CE, et al. Long-term safety and effectiveness of iron-chelation therapy with deferiprone for thalassemia major. N Engl J Med. 1998;339(7):417-423.

92. Pennell DJ, Berdoukas V, Karagiorga M, et al. Randomized controlled trial of deferiprone or deferoxamine in beta-thalassemia major patients with asymptomatic myocardial siderosis. Blood. 2006;107(9): 3738-3744.

93. Taher A, Sheikh-Taha M, Sharara A, et al. Safety and effectiveness of $100 \mathrm{mg} / \mathrm{kg} /$ day deferiprone in patients with thalassemia major: a two-year study. Acta Haematol. 2005;114(3):146-149.

94. Borgna-Pignatti C, Cappellini MD, De Stefano P, et al. Cardiac morbidity and mortality in deferoxamine- or deferiprone-treated patients with thalassemia major. Blood. 2006;107(9):3733-3737.
95. Piga A, Gaglioti C, Fogliacco E, Tricta F. Comparative effects of deferiprone and deferoxamine on survival and cardiac disease in patients with thalassemia major: a retrospective analysis. Haematologica. 2003;88(5):489-496.

96. Anderson LJ, Wonke B, Prescott E, Holden S, Walker JM, Pennell DJ. Comparison of effects of oral deferiprone and subcutaneous desferrioxamine on myocardial iron concentrations and ventricular function in beta-thalassaemia. Lancet. 2002;360(9332):516-520.

97. Berdoukas V, Chouliaras G, Moraitis P, Zannikos K, Berdoussi E, Ladis $\mathrm{V}$. The efficacy of iron chelator regimes in reducing cardiac and hepatic iron in patients with thalassaemia major: a clinical observational study. J Cardiovasc Magn Reson. 2009;11:20.

98. Al-Refaie FN, Wonke B, Hoffbrand AV. Deferiprone-associated myelotoxicity. Eur J Haematol. 1994;53(5):298-301.

99. Henter JI, Karlen J. Fatal agranulocytosis after deferiprone therapy in a child with Diamond-Blackfan anemia. Blood. 2007;109(12): 5157-5159.

100. Hoffbrand AV, Bartlett AN, Veys PA, O'Connor NT, Kontoghiorghes GJ. Agranulocytosis and thrombocytopenia in patient with BlackfanDiamond anaemia during oral chelator trial. Lancet. 1989; 2(8660):457.

101. Tondury P, Zimmerman A, Nielsen P, Hirt A. Liver iron and fibrosis during long-term treatment with deferiprone in Swiss thalassaemic patients. Br J Haematol. 1998;101(3):413-415.

102. Wanless IR, Sweeney G, Dhillon AP, et al. Lack of progressive hepatic fibrosis during long-term therapy with deferiprone in subjects with transfusion-dependent beta-thalassemia. Blood. 2002;100(5): 1566-1569.

103. Galanello R, Piga A, Alberti D, Rouan MC, Bigler H, Sechaud R. Safety, tolerability, and pharmacokinetics of ICL670, a new orally active ironchelating agent in patients with transfusion-dependent iron overload due to beta-thalassemia. J Clin Pharmacol. 2003;43(6):565-572.

104. Galanello R, Piga A, Cappellini MD, et al. Effect of food, type of food, and time of food intake on deferasirox bioavailability: recommendations for an optimal deferasirox administration regimen. $J$ Clin Pharmacol. 2008;48(4):428-435.

105. Nisbet-Brown E, Olivieri NF, Giardina PJ, et al. Effectiveness and safety of ICL670 in iron-loaded patients with thalassaemia: a randomised, double-blind, placebo-controlled, dose-escalation trial. Lancet. 2003;361(9369):1597-1602.

106. Chirnomas D, Smith AL, Braunstein J, et al. Deferasirox pharmacokinetics in patients with adequate versus inadequate response. Blood. 2009;114(19):4009-4013.

107. Taher A, Cappellini MD, Vichinsky E, et al. Efficacy and safety of deferasirox doses of $>30 \mathrm{mg} / \mathrm{kg}$ per $\mathrm{d}$ in patients with transfusiondependent anaemia and iron overload. Br J Haematol. 2009;147(5): $752-759$

108. Pennell DJ, Porter JB, Cappellini MD, et al. Efficacy of deferasirox in reducing and preventing cardiac iron overload in beta-thalassemia. Blood. 2010;115(12):2364-2371.

109. Pennell DJ, Porter JB, Cappellini MD, et al. Continued improvement in myocardial T2* over two years of deferasirox therapy in betathalassemia major patients with cardiac iron overload. Haematologica. 2011;96(1):48-54.

110. Wood JC, Kang BP, Thompson A, et al. The effect of deferasirox on cardiac iron in thalassemia major: impact of total body iron stores. Blood. 2010;116(4):537-543.

111. Pathare A, Taher A, Daar S. Deferasirox (Exjade) significantly improves cardiac T2* in heavily iron-overloaded patients with beta-thalassemia major. Ann Hematol. 2010;89(4):405-409.

112. Trad O, Hamdan MA, Jamil A, et al. Reversal of iron-induced dilated cardiomyopathy during therapy with deferasirox in beta-thalassemia. Pediatr Blood Cancer. 2009;52(3):426-428.

113. Kiguchi T, Ito Y, Kimura Y, Ohyashiki K. Restoration of cardiac function by an iron chelator, deferasirox, in a patient with aplastic anemia and cardiac iron overload. Int J Hematol. 2009;89(4):546-548. 
114. Rheault MN, Bechtel H, Neglia JP, Kashtan CE. Reversible Fanconi syndrome in a pediatric patient on deferasirox. Pediatr Blood Cancer. 2011;56(4):674-676.

115. Wei HY, Yang CP, Cheng CH, Lo FS. Fanconi syndrome in a patient with beta-thalassemia major after using deferasirox for 27 months. Transfusion. 2011;51(5):949-954.

116. Yacobovich J, Stark P, Barzilai-Birenbaum S, et al. Acquired proximal renal tubular dysfunction in beta-thalassemia patients treated with deferasirox. J Pediatr Hematol Oncol. 2010;32(7):564-567.

117. Bauters T, Mondelaers V, Robays H, Hunninck K, de Moerloose B. Gastric ulcer in a child treated with deferasirox. Pharm World Sci. 2010;32(2):112-113.

118. Kwiatkowski JL, Kim H-Y, Thompson AA. Chelation choices and iron burden among patients with thalassemia in the 21 st century: a report from the Thalassemia Clinical Research Network (TCRN) Longitudinal Cohort [Abstract]. Blood. 2009;114(22):4056.

119. Cappellini MD, Bejaoui M, Agaoglu L, et al. Prospective evaluation of patient-reported outcomes during treatment with deferasirox or deferoxamine for iron overload in patients with beta-thalassemia. Clin Ther. 2007;29(5):909-917.

120. Origa R, Bina P, Agus A, et al. Combined therapy with deferiprone and desferrioxamine in thalassemia major. Haematologica. 2005; 90(10):1309-1314.

121. Kattamis A, Ladis V, Berdousi H, et al. Iron chelation treatment with combined therapy with deferiprone and deferioxamine: a 12-month trial. Blood Cells Mol Dis. 2006;36(1):21-25.

122. Breuer W, Ermers MJJ, Pootrakul P, Abramov A, Hershko C, Cabantchik ZI. Desferrioxamine-chelatable iron, a component of serum non-transferrin-bound iron, used for assessing chelation therapy. Blood. 2001;97(3):792-798.

123. Link G, Konijn AM, Breuer W, Cabantchik ZI, Hershko C. Exploring the "iron shuttle" hypothesis in chelation therapy: effects of combined deferoxamine and deferiprone treatment in hypertransfused rats with labeled iron stores and in iron-loaded rat heart cells in culture. $J$ Lab Clin Med. 2001;138(2):130-138.

124. Tanner MA, Galanello R, Dessi C, et al. A randomized, placebocontrolled, double-blind trial of the effect of combined therapy with deferoxamine and deferiprone on myocardial iron in thalassemia major using cardiovascular magnetic resonance. Circulation. 2007; 115(14):1876-1884.
125. Tanner MA, Galanello R, Dessi C, et al. Combined chelation therapy in thalassemia major for the treatment of severe myocardial siderosis with left ventricular dysfunction. J Cardiovasc Magn Reson. 2008; 10:12.

126. Lai ME, Grady RW, Vacquer S, et al. Increased survival and reversion of iron-induced cardiac disease in patients with thalassemia major receiving intensive combined chelation therapy as compared to desferoxamine alone. Blood Cells Mol Dis. 2010;45(2):136-139.

127. Christoforidis A, Haritandi A, Tsatra I, Tsitourides I, Karyda S, Athanassiou-Metaxa M. Four-year evaluation of myocardial and liver iron assessed prospectively with serial MRI scans in young patients with beta-thalassaemia major: comparison between different chelation regimens. Eur J Haematol. 2007;78(1):52-57.

128. Otto-Duessel M, Brewer C, Gonzalez I, Nick H, Wood JC. Safety and efficacy of combined chelation therapy with deferasirox and deferoxamine in a gerbil model of iron overload. Acta Haematol. 2008;120(2):123-128.

129. Jetsrisuparb A, Komvilaisak P, Wiangnon S, Jetsrisuparb C. Retrospective study on the combination of desferrioxamine and deferasirox for treatment of iron-overloaded thalassemic patients: first evidence of more than 2 years. J Pediatr Hematol Oncol. 2010; 32(5):400-403.

130. Lal A, Sweeters N, Herz M, et al. Safety of combined chelation therapy with deferasirox and deferoxamine in transfusion-dependent thalassemia [Abstract]. Blood. 2009;114(22):2021.

131. Balocco M, Carrara P, Pinto V, Forni GL. Daily alternating deferasirox and deferiprone therapy for "hard-to-chelate" beta-thalassemia major patients. Am J Hematol. 2010;85(6):460-461.

132. Berdoukas V, Carson S, Nord A, et al. Combining two orally active iron chelators for thalassemia. Ann Hematol. 2010;89(11):1177-1178.

133. Rienhoff HY Jr, Viprakasit V, Tay L, et al. A phase 1 dose-escalation study: safety, tolerability, and pharmacokinetics of FBS0701, a novel oral iron chelator for the treatment of transfusional iron overload. Haematologica. 2011;96(4):521-525.

\section{Publish your work in this journal}

The Journal of Blood Medicine is an international, peer-reviewed, open access, online journal publishing laboratory, experimental and clinical aspects of all topics pertaining to blood based medicine including but not limited to: Transfusion Medicine; Blood collection, Donor issues, Transmittable diseases, and Blood banking logistics; Immunohematology; Artificial and alternative

\section{Dovepress}

blood based therapeutics; Hematology; Biotechnology/nanotechnology of blood related medicine; Legal aspects of blood medicine; Historical perspectives. The manuscript management system is completely online and includes a very quick and fair peer-review system. Visit http://www.dovepress.com/ testimonials.php to read real quotes from published authors. 